Article

\title{
A Thermal Simulation Tool for Building and Its Interoperability through the Building Information Modeling (BIM) Platform
}

\author{
Yudi Nugraha Bahar ${ }^{1, *}$, Christian Pere ${ }^{2}$, Jérémie Landrieu ${ }^{2}$ and Christophe Nicolle ${ }^{3}$ \\ 1 University of Bourgogne-France, Arts et Metiers ParisTech, LE2I, UMR CNRS 6306, \\ Institut Image, Chalon-sur-Saône, France \\ 2 Arts et Metiers ParisTech, CNRS, LE2I, Institut Image, 2 Rue T. Dumorey 71100 \\ Chalon-sur-Saône, France; E-Mails: christian.pere@ensam.eu (C.P.); \\ jeremie.landrieu@ensam.eu (J.L.) \\ 3 IUT Dijon-Auxerre, University of Bourgogne, Laboratoire LE2I, UMR CNRS 6306, France; \\ E-Mail: cnicolle@u-bourgogne.fr \\ * Author to whom correspondence should be addressed; E-Mails: ydnugra@gmail.com; \\ or yudi.nugraha-bahar@ensam.eu; Tel.: +33-602-309-823.
}

Received: 1 March 2013; in revised form: 25 April 2013 / Accepted: 14 May 2013 /

Published: 22 May 2013

\begin{abstract}
This paper describes potential challenges and opportunities for using thermal simulation tools to optimize building performance. After reviewing current trends in thermal simulation, it outlines major criteria for the evaluation of building thermal simulation tools based on specifications and capabilities in interoperability. Details are discussed including workflow of data exchange of multiple thermal analyses such as the BIM-based application. The present analysis focuses on selected thermal simulation tools that provide functionalities to exchange data with other tools in order to obtain a picture of its basic work principles and to identify selection criteria for generic thermal tools in BIM. Significances and barriers to integration design with BIM and building thermal simulation tools are also discussed.
\end{abstract}

Keywords: thermal simulation; BIM; interoperability; integration review 


\section{Introduction}

Thermal simulation tools are being used increasingly by all professions involved in the design of buildings. As building analysis software becomes more sophisticated, integrated, and easier to use, we are faced with the opportunity and the necessity to better our understanding of building performance in particular in terms of energy optimization.

Recognizing the implications of design decisions made by the different team members on the energy and environmental performance of the building engages all design team members in performing simulations. As a consequence, simulation tools have become recognized as design support tools within the Architecture-Engineering-Construction (AEC) industry [1].

From an AEC perspective, an advanced analysis of building thermal simulation in building modeling programs has become a critical part of high-performance buildings. The conceptual design phase of thermal modeling is used to provide the designer with first order of magnitude feedback about the impact of various building configurations on annual thermal performance [2].

Building thermal simulation is the dynamic analysis of the energy performance of buildings using computer modeling and simulation techniques. In this simulation, a calculation of building thermal loads and thermal consumption are involved in determining the thermal characteristics of the building and its building systems. Building thermal simulation is a powerful method for studying the thermal performance of buildings and to evaluate architectural design. Complex design problems can be investigated and their performance can be quantified and evaluated.

The thermal tool landscape for all building design professionals is diverse, ranging from research software to commercial products with thousands of users. They vary in their thermodynamic models, graphical user interfaces, purpose of use, life-cycle applicability, and ability to exchange data with other software applications. The fact that thermal simulation has become an integrated element of the design process has resulted in a diverse and growing user uptake, addressing the whole design team. On the other hand, due to the increasing importance of the decisions made early in the design process and their impact on energy performance and cost, several thermal simulation tools have been developed to perform early energy analysis independently.

With the development of building thermal tools incorporating local weather data and provision of local building materials, construction and codes, the number of tools users is growing enormously. Currently, there are more than 400 applications that can be applied to analyzing building energy and thermal simulation [3]. They are operated based on the manufacturers' instruction, spread all over the world and have their own standards. These various software applications need to be studied to determine which of them has performed a strong analysis of sustainable design as well as which provides a foundation for interoperability.

Today's emphasis on high-performance buildings makes it important to leverage BIM-based thermal analyses during design [4]. BIM technology involves the creation and use of coordinated, consistent information about a building. It allows for better decision-making, documentation and accurate prediction of building performance. Direct links between BIM and non-BIM modeling tools are an important ramification of BIM technology, enabling the creation of deliverables that have an explicit relationship to each other, resulting in a better coordinated and seamless data exchange that saves time, resources, effort and assures quality based liability and reduces risk [1]. 
Reviewing and comparing tools in this paper will allow identification of the data exchange among the commonly used building thermal tools according to the selection criteria as regards their interoperability through the BIM platform. The following covers most of the tools widely known in thermal simulation, which have been selected based on their popularity within the AEC community.

\section{Thermal Simulation Software and the BIM Platform}

\subsection{Overview of Building Thermal Simulation Tools}

Building thermal simulation tools predict the thermal performance of a given building and the thermal comfort of its occupants. In general, they support the understanding of how a given building operates according to certain criteria and enable comparisons of different design alternatives [5].

Evaluation of thermal comfort involves assessment of at least six factors: human activity levels, thermal resistance of clothing, air temperature, mean radiant temperature, air velocity and vapor pressure in ambient air [6].

Based on the evaluation in this study of various tools, some information required for thermal simulation includes as input data such as: building geometry, including the layout and configuration of the space (surfaces and volumes), grouping of rooms in thermally homogenous zones, building orientation, building construction, including the thermal properties of all construction elements, building usage including functional use, internal loads and schedules for lighting, occupants, and equipment, heating, ventilating, and air conditioning (HVAC) system type and operating characteristics, space conditioning requirements, utility rates, and weather data.

It is not easy to measure or to elaborate all of those values at a particular location in a building to create thermal comfort. Manual calculation of those values at every point within a building is almost impossible. One way to analyze thermal performance in buildings is by using thermal simulation programs that are capable of calculating all of those values accurately.

The accuracy of a thermal simulation result is determined by the input data. This input data mainly consists of the building geometry, internal loads, HVAC systems and components, weather data, operating strategies and schedules, and simulation specific parameters (Figure 1).

Figure 1. General input data of thermal simulation engines [5].

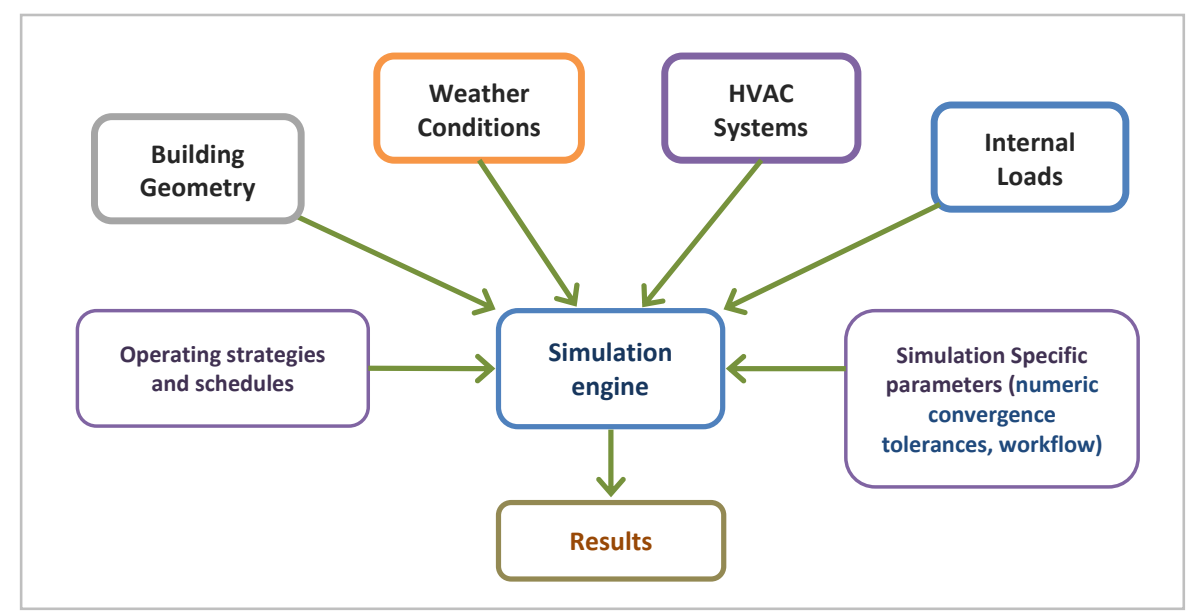


Most thermal simulation programs consist of what is referred to as an engine, which enables detailed thermal simulations based on simple text-based input and output files. These engines contain mathematical and thermodynamic algorithms that are used to calculate the thermal performance according to the underlying model of the engine. The simulation engine uses an input file (or files) of a defined format that contains a representation of the input. Based on this input the engine performs a simulation and writes its output into one or more output files [5]. These engines are mainly used to support the design process of a building by comparing energy consumption of different design alternatives.

Data come from internal and external parts of the building. The external loads, for example, are strongly influenced by weather and climate; collected and statistically assembled weather data are thus used in energy performance simulation. Weather data files are being created for design purposes in an increasing number of cities and regions around the world. These weather files do not reflect a specific year, but provide a statistical reference for the typical weather parameters of a specific location. During commissioning and operation, weather information can sometimes be measured directly at the building in question or at weather stations that are located close by. Internal loads such as loads from people, lights and equipment in a space depend greatly on the actual usage of the space and the behavior of its occupants. Figure 2 shows the grand picture of the thermal model production.

Figure 2. Workflow to produce a thermal simulation model.

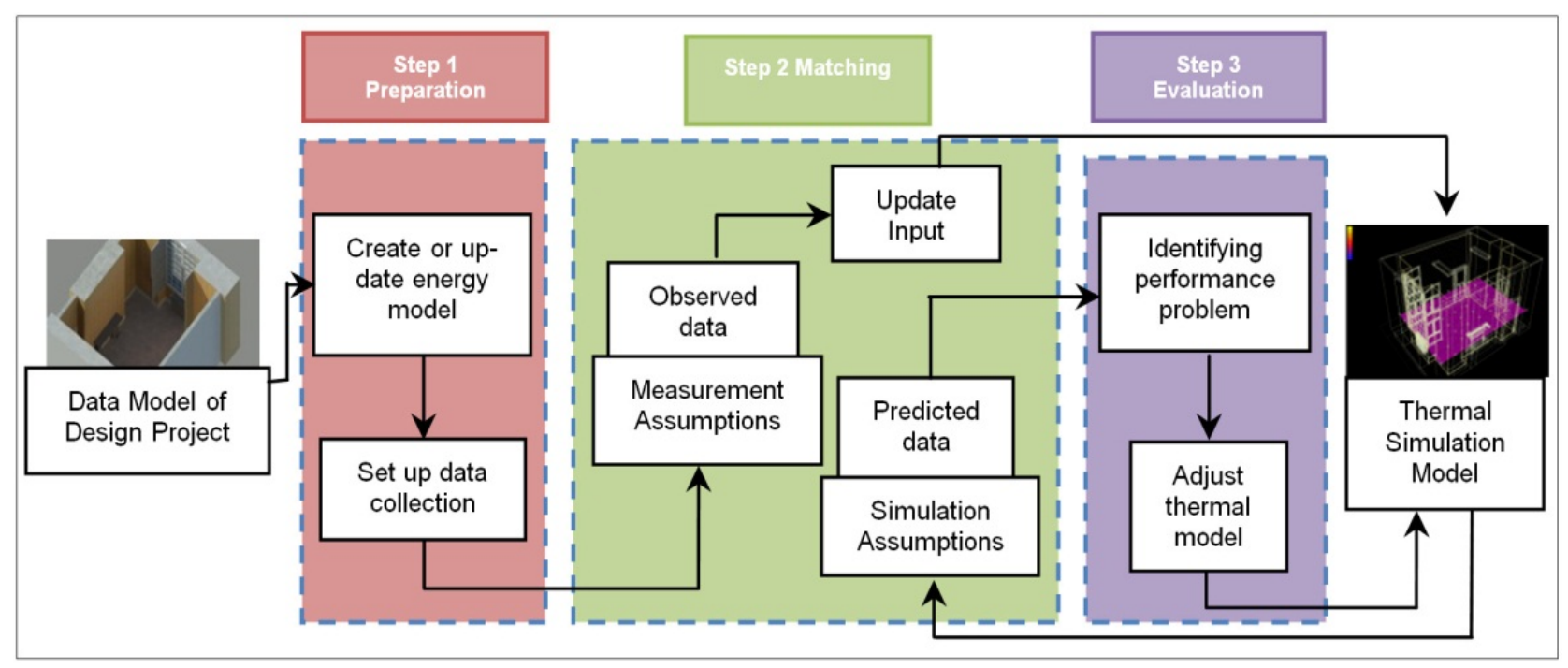

The result of the thermal simulation engine is an integrated model or comprehensive information and it should allow another program to read or to analyze further. The output data or the simulation result may be presented in a text, graph or code.

The output results may include:

- Assessment of the space and building thermal performance for compliance with regulations and targets;

- Overall estimate of the energy used by the space and for the building and an overall estimate of the energy cost;

- Time-based simulation of the energy use of the building and time-based estimate of utility costs;

- Lifecycle estimate of the energy use and cost for the building. 
Various thermal simulation tools are used to support almost all AEC design and management tasks, and the information entered into all of these tools describes the same physical project. However, this information is passed from one tool to the next by producing paper-based or electronic documents which can only be interpreted by people, who must re-enter relevant information into the next computer tool. This is because many thermal calculations and simulation software programs are part of the system of building energy performance and they generally receive geometry data from the design tool.

In addition, thermal simulation software sometimes does not present the overall results geometrically, but rather the forms of scale, charts or other notation codes. This format is sometimes not readable or hard to interpret by other software, which again creates more obstacles in the process of data exchange. This indicates that such tools are generally created as a multipurpose product or as a stand-alone tool and work independently. These kinds of applications store the building information in a native and proprietary format. In order to make this valuable information available to other project participants, these software applications must be able to understand the native formats of the other applications.

\subsection{Interoperability through BIM Platform}

Interoperability refers to the ability of two separate systems or software programs to communicate and exchange data with each other. The advantage that seamless data transfer offers is that this will remove redundancy and duplicate data generation, in analytical models and ensure the incorporation of sustainable features, at an early design stage [7]. Interoperability is one of the major themes of research and development in information technology for architecture, engineering, construction, and facilities management (AEC/FM) industries.

Interoperability - the possibility for information to flow from one computer application to the next throughout the lifecycle of a project - relies on the development and use of common information structures throughout the AEC/FM industry [8]. Exchanging models and other data between different software platforms remains one of the industry's biggest challenges on the way to fully integrated and collaborative project teams.

A survey of building performance tools by Attia [1] describes the major difference between the needs and priorities of architects and engineers concerning the interoperability of the building model. Architects exchange models with 3D drawing packages and the exchange of models with CAD programs. On the other hand, engineers defined the ability to exchange models with MEP drawing packages and the ability to exchange models for multiple simulation domains.

In a typical construction project, the basic structure organization of the team includes client, project manager, architect, civil engineer, structural engineer, mechanical engineer and electrical engineer. It is now possible for them to work together within the model in an improved coordination and organization. This interaction depends on multi party tools to success. The method is called Integrated Design Process (IDP). The IDP's purpose is to utilize a collaborative team effort to prepare design and construction documents that result in an optimized project system solution [9,10]. As building codes are updated to take building performance into account, there is an increasing obligation on the part of designer to provide higher degrees of insight regarding building outcomes. The design team needs to define technology standards to encourage opportunities for increased project and data flexibility. 
BIM has the real role in the IDP. BIM and web-based project management software has created a solid platform for an improved, more efficient means of collaboration between all the parties involved in project delivery.

BIM is a shared digital representation of the physical and functional characteristics of a facility founded on open standards for interoperability; a shared knowledge resource for information about a facility forming a reliable basis for decisions during its life-cycle from inception onward, a basic premise is the collaboration between different stakeholders at different phases of the life cycle of a facility to insert, extract, update or modify information in the process to support and reflect the roles of that stakeholder [11].

BIM is a data-rich, object-based, intelligent digital representation of a facility which includes not only 3D geometric models (which, therefore, are capable of directly generating 2D and 3D drawings), but also specific information on a wide range of building elements and systems associated with a building (e.g., wall constructions, material properties, spaces and thermal zones, heating, ventilating, and air conditioning (HVAC) systems, geospatial information, space loads, etc.). This information can be used for other building analysis purposes [12]. In most cases, only the mechanical engineer or modeling engineer completes energy simulations. To achieve a comprehensive thermal building, this organizational structure requires excellent communication between groups, particularly at the initial design stages. However, with the BIM concept, communication and data exchange among all parties can reach a high degree in particular, redundant building data can be significantly reduced by using BIM [13].

The use of BIM as a central repository for the building project information has revolutionized information for project management. The AEC industry is constantly looking for new ways to improve collaboration and interoperability of BIM platforms through new technology and open-standards programs to be able to more readily share information among the various design and simulation platforms that are available on the market today.

A model-based approach to interoperability requires information structures that are standardized throughout the industry (Figure 3).

Figure 3. Interoperability and Architecture-Engineering-Construction (AEC) Practice [14].

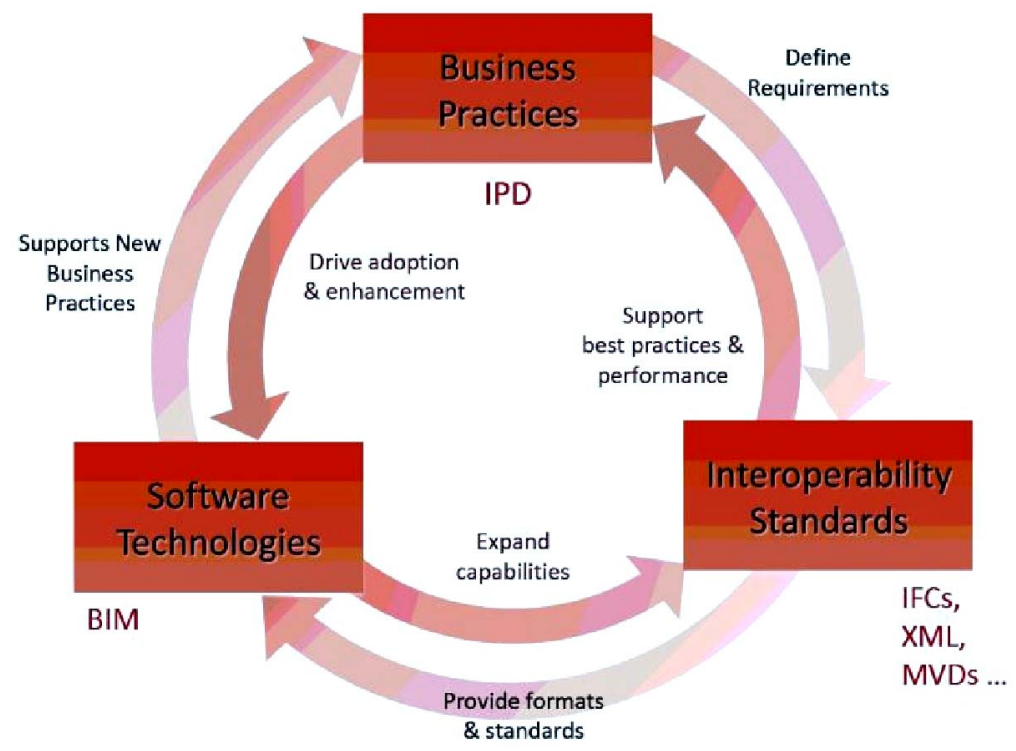


Significant progress has been made in this common data exchange, particularly in multi-platform interoperability. Currently, the Industry Foundation Class (IFC) and Green Building XML (gbXML) are two prevalent informational infrastructures in the AEC industry. IFC and gbXML are both used for common data exchange between AEC applications such as CAD and building simulation tools $[15,16]$. Both IFC and XML create a common language to transfer BIM information between different BIM and building analyses applications while maintaining the meaning of different pieces of information in the transfer. This reduces the need to remodel the same building in each different application. It also adds transparency to the process [12].

IFC represents a data schema for sharing construction and facility management data across various applications used in the AEC/FM industry domain. It is an object-oriented data schema based on class definitions representing the objects (such as building elements, spaces, properties, shapes, etc.) that are used by different software applications in the construction or facility management project. IFC has variant data file formats that facilitate exchange between applications, e.g., .ifc, which is the default IFC exchange format, .ifcXML, IFC data file using the XML document structure, and .ifcZIP, IFC data file using the PKzip $2.04 \mathrm{~g}$ compression algorithm [11].

The AEC Industry has yielded the proprietary development of energy export and import capabilities in several major engineering modeling tools. A number of these involve the use of gbXML. With the development of integration modules inside major engineering analysis tools, gbXML has become the defacto industry standard schema [17]. GbXML is based on the XML (Extensible Markup Language) deployed by Green Building Studio Inc. It has the ability to carry building environmental sensing information. It also has a global "language" format, with consistent syntax and can potentially represent any computational building model through translation using appropriate mapping engines.

In terms of geometry, the generic approach of IFC has the ability to represent any shape of building geometry, while gbXML only accept the rectangular shape. CAD—magazine has claimed that the IFC format is very powerful but rather few thermal simulation tools use it. They prefer the gbXML due to its capacity to provide a satisfactory answer [18].

IFC uses a "top-down" and relational approach, which yields a relatively complex data representation schema and a large data file size. Conversely, gbXML adopts a "bottom-up" approach, which is flexible, open source, and a relatively straight forward data schema. The "top-down" approach can trace back all the semantic changes when one value of the element in the schema is changed [15].

The technology for exchanging information using IFC has now been established, but many areas require additional development before comprehensive interoperability solutions are reached. These areas include: extending the scope to include a broader range of project information, for more types of projects, and more types of information; developing the exchange mechanisms layer below the data standards and the formalized transactions layer above; developing the range of software applications that implement model-based interoperability; and re-examining project management practices based on new integration technologies [8].

\subsection{Thermal Simulation Tools and Their Interoperability}

A multiplatform concept is a fundamental criterion for assessing thermal tools because it allows multidisciplinary storing of information with one virtual representation. The reliability of data 
exchange and the straightforward nature of the tool, as well as user-friendly interfaces are major aspects of the practical use of thermal tools. The success of interoperability is limited to the detailed design phase because it ensures access for the design team to building thermal model, only after the whole building design has been completed. The huge amount of input data, the availability of rich 3D geometry models, effective data exchange and software interfaces are crucial to enable faster and more reliable thermal performance simulation analysis.

With the increasing complexity of the geometry of buildings, the simulation tool requires an appropriate geometric model. For the comparison of simulated results with measured data, the simulation tool requires an integrated simulation. This means that it requires the feedback from the HVAC system response to the space or zone [5]. Thermal zones are an agglomeration of one or more spaces with similar thermal characteristics such as orientation, size, HVAC system type, and internal loads.

The IFC provides the data concerning the semantics and syntax of construction elements; a comprehensive set covering tangibles and abstract entities such as windows, doors, walls, spaces, furnishing elements, etc. [19]. Thermal characteristic is another kind of IFC product. It is included in a sub division in another concept of basic class for physical objects, along with spatial elements, physical elements, structural analysis items, and other concepts which are associated with materials, shape representations, and placement in space.

IFC and gbXML formats for thermal analysis can read as some distribution elements (HVAC, electricity, plumbing) which are organized according to the concept of ports, where elements may have specific connections for various services in the building, and be connected together to form a system. Since it is possible to write IFC and interfaces to HVAC design and simulation tools and cost estimation tools, it is possible to import building geometry data from design tools, which allows the exchange of thermal data (HVAC data), and performance specification, construction properties, and geometry.

Figure 4 illustrates the workflow that defines the area input of BIM in the thermal simulation process. The first step is to define the location of the building that provides a link to weather data. The second step will ideally provide information through importing data from a BIM. This information includes the needed 3D geometry information, construction and material definitions, and space types that are typically defined by the architect. A simplification of geometry might need to comply with the geometry definition of the relevant thermal performance simulation tool. Based on these geometry definitions, the user interface would be able to aggregate spaces into zones (as well as subdivide spaces into zones). A "thermal zone" which may cover one or more rooms, is an important basic structure for thermal simulation. In this process, the data will bind into an appropriate zone by the IFC or gbXML format, for example. In the next step, space loads (such as lighting loads) could be assigned to the specific appropriate space types that have been imported via the BIM link. However, this workflow might not immediately smooth management interoperability. The experiences of many BIM based projects show that interoperable thermal analysis software is not enough for the management of thermal performance during the building process, but also requires tools to manage different revisions of BIMs, to compare thermal performance of these revisions and to visualize this in an easy-to-understand way [20].

An advanced interoperability method was developed by Welle et al. [4], with ThermalOpt. ThermalOpt is a methodology for automated BIM-based multidisciplinary thermal simulation that attempts to mitigate several technical barriers to BIM-based multidisciplinary thermal simulation 
encountered in practice today. In this method, the user can start the process by building a parametric BIM model and assigning analysis information using the BIM Application GUI (Digital Project) and the Analysis Application GUI (ThermalSim Plugin). When the user initializes the trade study, in this case an optimization, the BIM information is passed via IFC (DP Plugin) to a middleware (IFC2ThermalSim Plugin) for pre-processing, then to an energy simulation environment (EnergyPlus Wrapper) and a day lighting simulation environment (Radiance Wrapper) for analysis.

Figure 4. An ideal workflow for energy performance in thermal simulation tools [5].

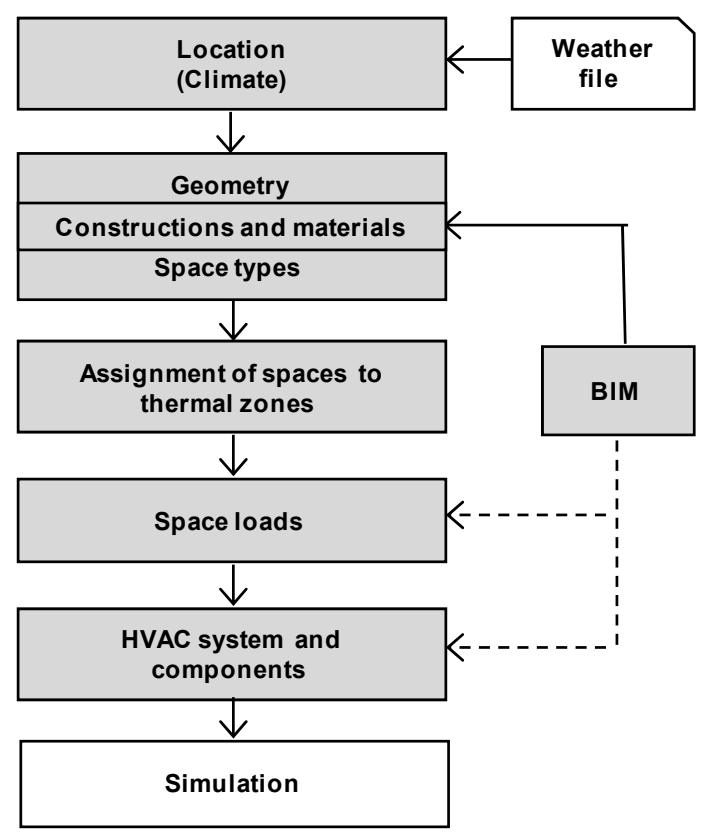

ThermalOpt enables an automated methodology to pre-process, configure, execute, and post-process a BIM-based multidisciplinary thermal simulation process that may be used during early design. This method is capable of significantly reducing the time to pre-process, configure, execute, and post-process this design task while improving its consistency over conventional methods [4].

\section{Interoperability Review of the Most Applicable Building Thermal Simulation Tools in the AEC Community}

There exist today a large number of simulation tools as BIM applications concerning thermal simulation in buildings. Crawley et al. [21] have detailed the functionality and differences of 20 major building simulation tools. Attia [1] described eight building performance simulation tools according to selection criteria and user surveys. Dubois et al. [22] reviewed the existing computer tools widely used by architects today, covering a total of 56 computer programs which were classified into three categories: CAAD (computer-aided architectural design) tools, Visualization tools, and simulation tools. Based on these reports, as well as on the analysis of recent trends in thermal tools, this report reviewed certain selected tools that are most applicable to the BIM application. The present review focuses on tools that can be used at multiple stages of the life-cycle and that provide functionalities to exchange data with other tools in open standard building information models, in this case IFC and gbXML. 
Thus, the goals of the review are to draw a picture of the principles of data exchange in thermal simulation software and to compare the interoperability challenges and opportunities of using selected thermal tools and building performance simulation tools that integrate thermal analysis.

All data for the identification of the tools have been gathered and shortlisted in the chart below. The tools listed were selected as those most applicable by professional users in the AEC community (whether they focus on the BIM platform or not). These applications are DPV (Design Performance Viewer), Design Builder, Ecotect, EnergyPlus, eQUEST, EcoDesigner, ESP-r, Green Building Studio, Lesosai, IDA ICE, IES VE, TRACE700, TRNSYS and Riuska.

They have also been tested on their reliability according to the basic principal of thermal simulation and data exchange. The test is to illustrate interchanged between BIM design and thermal tools. The websites of each program were visited and a database with key information was selectively built and enriched by journal updates. In addition, scientific articles about the selected programs were consulted when necessary. As a thermal simulation tool is used within a design process that involves other software (e.g. CAD, spreadsheets, presentation, etc.) the assessment of the compatibility and interoperability of each tool focuses on typical software used in the industry (Table 1).

Table 1. Interoperability of the thermal tools investigated.

\begin{tabular}{|c|c|c|c|c|}
\hline Tool & Application & Input data & Output data & $\begin{array}{l}\text { BIM based } \\
\text { geometry import }\end{array}$ \\
\hline $\begin{array}{l}\text { DPV (Design } \\
\text { Performance } \\
\text { Viewer) }\end{array}$ & $\begin{array}{l}\text { Environmental design, thermal design } \\
\text { and analysis, heating and cooling loads, } \\
\text { energy cost, Exergy/ } \mathrm{CO}_{2} \text {, life cycle } \\
\text { assessment, scheduling. }\end{array}$ & $\begin{array}{l}\text { CAD-BIM, } \\
\text { revit }\end{array}$ & - & $\begin{array}{l}\text { The building model } \\
\text { is directly built in } \\
\text { the CAD-BIM } \\
\text { environment. }\end{array}$ \\
\hline DesignBuilder & $\begin{array}{l}\text { Environmental design, 3D Model (3D } \\
\text { Design), thermal design and analysis, } \\
\text { heating and cooling loads, natural and } \\
\text { artificial lighting, Internal air, mean radiant } \\
\text { and operative temperatures, humidity, } \mathrm{CO}_{2} \\
\text { emissions, solar shading, heat transmission, } \\
\text { solar shading, scheduling. }\end{array}$ & $\begin{array}{l}\text { gbXML, } \\
. d x f, . p d f, \\
. b m p, . j p g\end{array}$ & $\begin{array}{l}\text { CAD: } \\
\text { AutoCAD, } \\
\text { Microstation, } \\
\text { SketchUp using } \\
\text { 3-D dxf, .epw, } \\
\text {.csv, .tmy, .tmy2 }\end{array}$ & $\begin{array}{l}\text { Provides } \\
\text { interoperability } \\
\text { with BIM models } \\
\text { through its .gbXML } \\
\text { import capability. }\end{array}$ \\
\hline Ecotect & $\begin{array}{l}\text { Environmental design, 3D Model (3D } \\
\text { Design), thermal design and analysis, } \\
\text { heating and cooling loads, Validation; } \\
\text { Solar control, overshadowing, prevailing, } \\
\text { winds \& air Flow, natural and artificial } \\
\text { lighting, life cycle assessment, life cycle } \\
\text { costing, scheduling, geometric and } \\
\text { statistical acoustic analysis. }\end{array}$ & $\begin{array}{l}. d w g, \\
. i f c, g b X M L, \\
. o b j, 3 D S, \\
. x m l, \\
\text { ASCII, etc. }\end{array}$ & $\begin{array}{l}\text { Metafiles, } \\
\text { Bitmaps or } \\
\text { animations. } \\
\text { RADIANCE, } \\
\text { POV Ray, } \\
\text { VRML, } \\
\text { AutoCAD dxf, } \\
\text { EnergyPlus, } \\
\text { ESP-r, ASCII } \\
\text { Mod files, } \\
\text { XML, etc. }\end{array}$ & $\begin{array}{l}\text { Imports } \\
\text { CAD-BIM models } \\
\text { from most CAD } \\
\text { software }\end{array}$ \\
\hline
\end{tabular}

Energy performance, simulation, energy use analysis, conceptual design performance analysis, 3D Model (3D

eQUEST Design), thermal design and analysis, heating and cooling loads, Solar control, gbXML, dxf, gbXML, .dwg, dxf .xls Support gbXML overshadowing, Lighting system, life cycle assessment, life cycle costing, Scheduling. 
Table 1. Cont.

\begin{tabular}{|c|c|c|c|c|}
\hline Tool & Application & Input data & Output data & $\begin{array}{l}\text { BIM based } \\
\text { geometry import }\end{array}$ \\
\hline EnergyPlus & $\begin{array}{l}\text { Energy Simulation, thermal design and } \\
\text { analysis, Heating and cooling loads, } \\
\text { Validation; Solar control, } \\
\text { Overshadowing, Natural and artificial } \\
\text { lighting, Life cycle assessment, Life } \\
\text { cycle costing, Scheduling. }\end{array}$ & $\begin{array}{l}\text { ifc, gbXML, } \\
\text { text }\end{array}$ & ASCII & $\begin{array}{l}\text {.ifc compatible. } \\
\text { (BIM Application) }\end{array}$ \\
\hline EcoDesigner & $\begin{array}{l}\text { Energy balance evaluation, } \mathrm{CO}_{2} \text {, } \\
\text { overshadowing, heating, cooling, } \\
\text { lighting, water use, Life cycle costing, } \\
\text { Scheduling, prime energy usage } \\
\text { (gas, energy, electricity etc.) }\end{array}$ & gbXML & $\begin{array}{l}\text { gbXML, } \\
\text {.pdf }\end{array}$ & $\begin{array}{l}\text { Provides another } \\
\text { dimension in the } \\
\text { BIM environment } \\
\text { for the architect in } \\
\text { shaping his design }\end{array}$ \\
\hline ESP-r & $\begin{array}{l}\text { Environmental Design, 3D Design, } \\
\text { thermal design and analysis, heating and } \\
\text { cooling loads, Solar control, lighting, } \\
\text { natural ventilation, combined heat and } \\
\text { electrical power generation and } \\
\text { photovoltaic facades, acoustic analysis, } \\
\text { life cycle and environmental impacts } \\
\text { assessments. }\end{array}$ & XML & $\begin{array}{l}\text { XML, csv, } \\
\text { VRML }\end{array}$ & no \\
\hline $\begin{array}{l}\text { Green Building } \\
\text { Studio }\end{array}$ & $\begin{array}{l}\text { Environmental Design, thermal analysis, } \\
\text { annual energy consumption (electric and } \\
\text { gas), Carbon emissions, day lighting, } \\
\text { water usage and cost, Life cycle costing, } \\
\text { natural ventilation. }\end{array}$ & $\begin{array}{l}\text { gbXML- } \\
\text { enabled } \\
\text { BIM or } \\
\text { 3D-CAD }\end{array}$ & gbXML, VRML & $\begin{array}{l}\text { Supports gbXML } \\
\text { format and has easy } \\
\text { interoperability with } \\
\text { BIM Application }\end{array}$ \\
\hline Lesosai & $\begin{array}{l}\text { thermal design and analysis, Heating and } \\
\text { cooling loads, Solar control, } \mathrm{CO}_{2} \text {, natural } \\
\text { and artificial lighting, life cycle } \\
\text { assessment, life cycle costing, Scheduling. }\end{array}$ & $\begin{array}{l}\text { gbXML, } \\
. n b d m, \\
\text {.skp }\end{array}$ & $\begin{array}{l}. x l s, . x m l, . p d f, \\
. b l d, . t x t \text { files }\end{array}$ & $\begin{array}{l}\text { Supports gbXML } \\
\text { format and has easy } \\
\text { interoperability with } \\
\text { BIM Application }\end{array}$ \\
\hline IDA ICE & $\begin{array}{l}\text { Environmental design, 3D Model (3D } \\
\text { Design), thermal design and analysis, } \\
\text { heating and cooling, Solar and shading, } \\
\text { surface transmissions, air leakage, cold } \\
\text { bridges and furniture, lighting, Air } \mathrm{CO}_{2} \\
\text { and moisture levels, Energy costing. }\end{array}$ & $\begin{array}{l}. i f c, . d x f, \\
. d w f, .3 \mathrm{ds} \\
. \operatorname{cgm}, . c m x \\
. \operatorname{dgn}\end{array}$ & $\begin{array}{l}. \text { html, .doc, .xls, } \\
. j p e g, . j p g, . p n g \\
. t i f f, . b m p\end{array}$ & $\begin{array}{l}\text {.ifc compatible. } \\
\text { (BIM Application) }\end{array}$ \\
\hline IES VE & $\begin{array}{l}\text { Thermal design and analysis, heating } \\
\text { and cooling loads, } \mathrm{CO}_{2} \text {, Validation; } \\
\text { Solar, Shading, Lighting, Airflow, } \\
\text { Life cycle costing, Scheduling, } \\
\text { fire evacuation. }\end{array}$ & $\begin{array}{l}\text { gbXML, } \\
. d x f \\
. d w g\end{array}$ & .ve & $\begin{array}{l}\text { Supports gbXML } \\
\text { format and has easy } \\
\text { interoperability with } \\
\text { BIM Application }\end{array}$ \\
\hline TRACE 700 & $\begin{array}{l}\text { Environmental design, 3D Model (3D } \\
\text { Design), thermal design and analysis, } \\
\text { heating and cooling, life cycle costing, } \\
\text { plants system. }\end{array}$ & gbXML & $\begin{array}{l}. p d f, . r t f \\
. t x t, . d o c \\
. x l s\end{array}$ & $\begin{array}{l}\text { Supports gbXML } \\
\text { format and has easy } \\
\text { interoperability with } \\
\text { BIM Application }\end{array}$ \\
\hline
\end{tabular}


Table 1. Cont.

\begin{tabular}{|c|c|c|c|c|}
\hline Tool & Application & Input data & Output data & $\begin{array}{l}\text { BIM based } \\
\text { geometry import }\end{array}$ \\
\hline TRNSYS & $\begin{array}{l}\text { Environmental design, 3D Model (3D } \\
\text { Design), thermal design and analysis, } \\
\text { heating and cooling loads, Solar control, } \\
\text { overshadowing, prevailing winds \& air } \\
\text { Flow, electrical, photovoltaic, hydrogen } \\
\text { systems, Life cycle costing. }\end{array}$ & $\begin{array}{l}. s k p, \text { ASCII, } \\
. x m l\end{array}$ & $\begin{array}{l}\text { ASCII } \\
\text { (Simulation } \\
\text { Studio Tool : } \\
\text { HTML, C++) }\end{array}$ & no \\
\hline Riuska & $\begin{array}{l}\text { Environmental design, 3D Model, } \\
\text { thermal design and analysis, heating } \\
\text { and cooling loads, validation; Solar } \\
\text { control, overshadowing, lighting, } \\
\text { life cycle assessment, life cycle } \\
\text { costing, scheduling. }\end{array}$ & ifc & iff & $\begin{array}{l}\text {.ifc compatible. } \\
\text { (BIM Application) }\end{array}$ \\
\hline
\end{tabular}

This review indicates that there are many energy simulation tools that are used particularly for thermal calculation. In some cases, thermal tools are not stand-alone, but integrated into or as a part of design software. Among these thermal tools, the link with BIM applications is the most interesting possibility in terms of interoperability for energy simulations. These applications are DPV, Design Builder, Ecotect, EnergyPlus, eQUEST, EcoDesigner, Green Building Studio, IDA ICE, IES VE, and Riuska.

- The Design Performance Viewer (DPV) is an ongoing research project begun in 2007, conducted at the Institute of Technology in Architecture (ITA) at the Department of Architecture at the ETH Zurich [23]. The DPV enables instantaneous energy and $\mathrm{CO}_{2}$ emission calculations and the graphical visualization of the resulting performance indices of a building design focused not only on form and geometry, but also viewed in an integrated way. Relevant energy data is calculated and visualized in real time. The user can immediately see how measures concerning building geometry, construction and technical systems affect energy and exergy consumption as well as costs. DPV is directly linked to the library of the CAD-BIM environment. To deliver immediate performance feedback, the DPV is integrated into the BIM-modeling environment (Autodesk Revit).

- DesignBuilder has been specifically developed around EnergyPlus [24], allowing input of all of the EnergyPlus fabric and glazing data. As an interface to EnergyPlus, it builds models for energy simulation using EnergyPlus. DesignBuilder allows compliance with energy certificates in UK, alternatives comparison and parametric analysis of different design parameters. It provides a wide range of environmental performance simulations in a 3D interface, also performing daylight analysis. Design Builder allows import of 3D architectural models created in Revit, ArchiCAD or MicroStation and other 3D CAD systems supporting .gbXML, and dxf data exchange.

- Ecotect was developed by Dr. Andrew Marsh and Square One Research Ltd. that was acquired by Autodesk. Ecotect analysis offers a wide range of simulation and building energy analysis functionalities to visualize and simulate a building's performance within the context of its 
environment [25]. The new Ecotect Analysis includes an expanded array of environmental analysis and simulation capabilities including shadows and reflections, shading design, solar analysis, photovoltaic array sizing and load matching, lighting design, right-to-light analysis for neighboring buildings, acoustic analysis, thermal analysis, and ventilation and airflow [26].

Ecotect has added the support for IFC and gbXML schemas since the release of the newest version 5.6. Ecotect can perform more applications: daylight analysis, sound analysis and more visualization. It can import CAD-BIM models from most CAD software; Revit, AutoCad, ArchiCad and 3DsMax.

Ecotect can export to a wide range of other programs and CAD formats. Export is supported to Radiance (ray-traced rendering), POV-Ray and .wrl, .dxf (compatible with most CAD software), GBS, EnergyPlus and eQUEST.

- EnergyPlus is an energy analysis and thermal load simulation program. EnergyPlus is a new-generation building energy simulation program based on DOE-2 and BLAST, with numerous added capabilities. Released in April 2001, the program was developed jointly by Lawrence Berkeley National Laboratory, the University of Illinois, the U.S. Army Construction Engineering Research Laboratory, GARD Analytics, Inc., Oklahoma State University and others, with support from the U.S. Department of Energy, Office of Building Technology, State and Community Programs [27].

EnergyPlus has data exchange via IFC, gbXML, and dxf. All CAD programs linked to EnergyPlus through a plugin or export function (ArchiCAD, Google/Trimble SketchUp, MicroStation, Revit, Vectorworks) allow active solar system calculation. EnergyPlus and Green Building Studio can operate or allow performing of thermal simulations from Google/Trimble SketchUp (.skp) and Excel (.xls), the non-BIM application.

- eQUEST was developed by James J. Hirsch \& Associates in collaboration with Lawrence Berkeley National Laboratory, with LBNL DOE-2 [28]. eQUEST is based on DOE-2 dynamic energy simulation software and calculates heating and cooling loads during a year based on a data-entry building description. eQUEST has the ability to import .dwg files. It is also possible to export analysis results in Excel (.xls) format. eQUEST can import building geometry via $\mathrm{gbXML}$ but it is not as generic as the IFC format.

- EcoDesigner is bound up with archiCAD. EcoDesigner integrates the VIP web engine directly into ArchiCAD's program core, but is configured to act as a design aid rather than a simulation tool. Although not as comprehensive as Ecotect, EcoDesigner provides ArchiCAD users with basic energy- and carbon-checking functions. EcoDesigner, EnergyPlus, Green Building Studio and Ecotect can link with ArchiCAD BIM.

- Green Building Studio (GBS) is a web-based energy analysis service supplied by Autodesk [29]. GBS is an analysis tool, which performs whole building energy analysis but does not provide a 3D interface. The model has to be created by another software program which can export to the .gbXML format. GBS does not support the .ifc format but provides easy interoperability with BIM tools and other software; it offers a great interoperability with Autodesk Revit, ArchiCad, Ecotect, eQuest, and EnergyPlus. Various file formats are supported, such as .gbXML, VRML, and some weather files. 
- IDA Indoor Climate and Energy is a simulation application for the accurate study of the thermal indoor climate of individual zones (thermal zones) within a building, as well as the energy consumption for the entire building [30]. IDA ICE was developed by the EQUA Simulation Technology Group in Stockholm [31]. IDA ICE supports gbXML and IFC as BIM interfaces. IDA ICE can import .ifc, .dxf, .dwf, .3ds, .cgm, .cmx, .dgn, .drw, .gbr, .svg, .pcl, .prn, .prt, .pct, .plt, .wpg, .vwpg, .bmp, .jpeg, .jpg, .png, .pcx, .tiff, .tif, .pcd, .tga, .emf, .wmf and export is possible to .html, .doc, .xls, .jpeg, .jpg, .png, .tiff, .bmp and clipboard. IDA ICE imports all versions of .ifc so the program is .ifc compatible.

- VE (Virtual Environment) was developed by IES (Integrated Environmental Solutions) in Scotland [32]. It is an integrated system that operates all of its building simulations from a central building model. The software allows the assessment of performance and providing feedback on a building energy consumption and carbon dioxide emission. IES VE supports gbXML and dxf and it can import files from Revit, ArchiCad and as a plug-in of Google SketchUp. Vectorworks BIM software is interoperable with IES VE and Autodesk Ecotect Analysis.

- RIUSKA was developed by Granlund. The core of the software is the widely used DOE 2.1E simulation program [33]. It calculates indoor temperatures, occupancy, lighting, equipment gains, and the heating and cooling of individual spaces, and can be used to compare and dimension HVAC systems as well as to calculate the energy consumption of whole buildings. Riuska allows the direct transfer and reuse of digital building geometry data from IFC-compliant architectural software (Autodesk Revit, ArchiCAD, Nemetschek`s Allplan and Visio). RIUSKA can also export main spatial thermal parameters to IFC to be used in other applications, such as building services system modeling or requirement management tools.

(Limitation: This test and review covers most of the tools widely known and used by the AEC community. However, a comprehensive review of all available tools world-wide is nearly impossible due to the amount of information that would need to be collected).

The review has indicated that there are many design or modeling tools commonly used today include some form of algorithm for the prediction of building energy simulations. These include the three CAD software programs widely used by the AEC community: Revit, Archicad, and Sketch-Up. Thus, to obtain thermal simulation results, the thermal analysis proceeds either by the thermal engine that has been integrated into them (in this case the mass model is automatically converted into the energy model) or by transferring it to another thermal engine that is interoperable with BIM models. Fortunately, many manufacturers and third-party vendors are beginning to provide BIM object libraries populated with many of the physical and analytical characteristics needed to perform HVAC analysis. This review has also indicated that when the model is used to perform analysis, either an integrated analytical modeling tool within the BIM software runs the analysis, or the information in the model is exported out of the physical model in a file format that the analytical modeling software accepts. Two of the most common formats are IFC and gbXML (Figure 5).

Revit (Architecture and MEP) is a tool supplied by Autodesk, purposely built for BIM. Green Building Studio and Ecotect are integrated with Revit, now known as Project Vasari. Revit links with 
DPV (Design Performance Viewer), Design Builder, EnergyPlus, eQUEST, ESP-r, Lesosai, TRNSYS, IDA ICE, IES VE, TRACE700 and Riuska.

Figure 5. Summary of data exchange between modeling tools and thermal simulation tools. The linkages include those as interface, add-on or plug-in. The data exchange is conducted in various formats, primarily by IFC and gbXML.

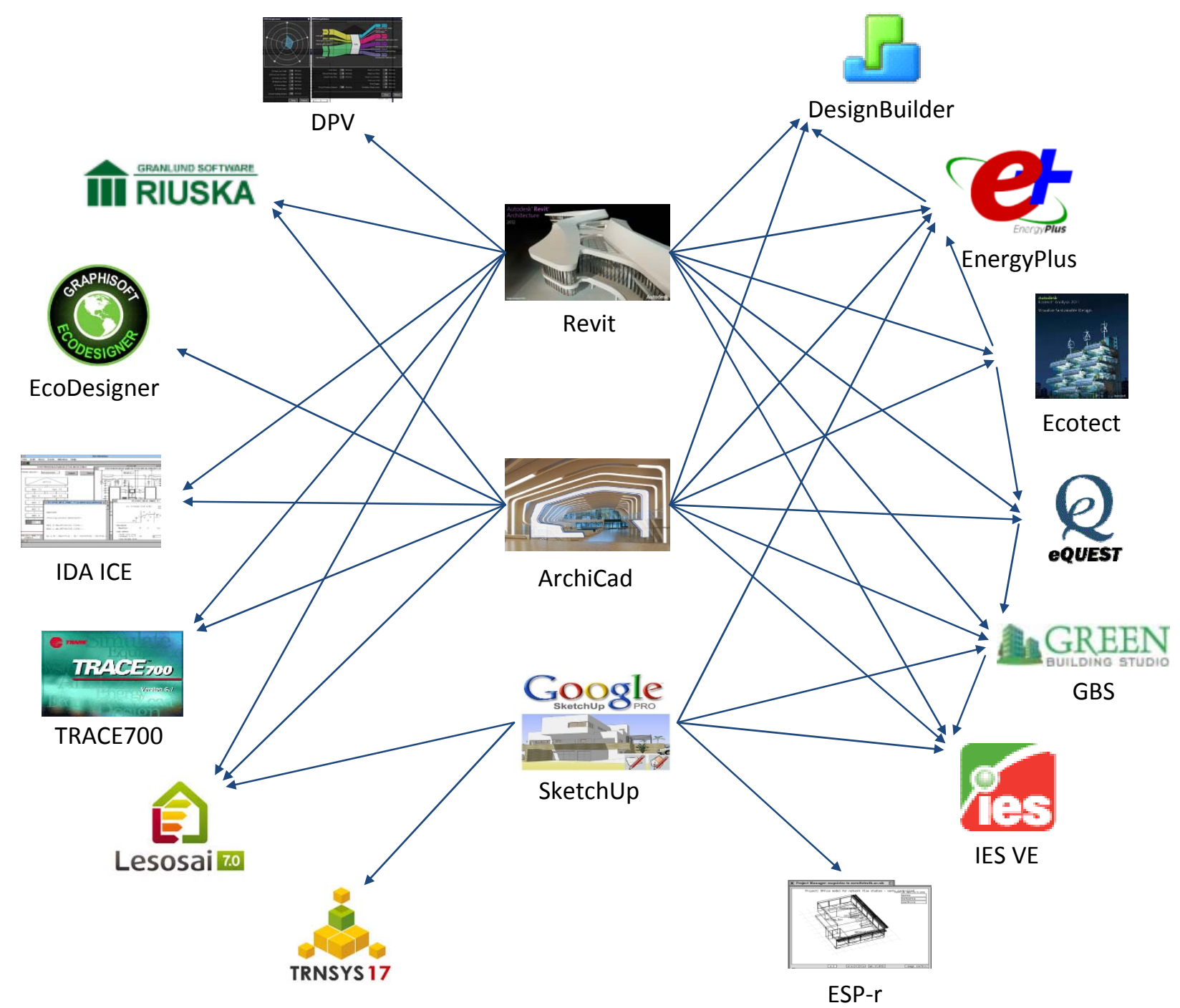

ArchiCAD is an architectural BIM/CAD tool supplied by Graphisoft/Abvent. EcoDesigner is built into ArchiCAD as an interface. The ArchiCAD BIM program also links with Design Builder, Ecotect, EnergyPlus, Green Building Studio, Lesosai, TRNSYS, IDA ICE, IES VE, TRACE700, and Riuska. Within ArchiCAD, it is possible to create zones and then export the simplified energy model into Ecotect using Green Building Studio's .gbXML format, where the energy analysis and solar design can be completed.

Google/Trimble SketchUp does not offer direct support for BIM. SketchUp integrates with certain plugins: IES VE-Ware, Lesosai and Trnsys. SketchUp has links to ESP-r, and also integrates OpenStudio, a free plugin for the SketchUp 3D drawing program. OpenStudio is an open source tool to support whole building energy modeling using EnergyPlus. The OpenStudio plug-in automatically generates the input for an EnergyPlus object when the user draws a surface in SketchUp. This plugin 
makes it easy to create and edit building geometry in EnergyPlus input files. It allows the launching of EnergyPlus simulations and visualization of the results without leaving SketchUp. This plugin performs energy analysis on a SketchUp design by adding attributes to the geometry and then connecting it to Green Building Studio's web service, or other analysis applications that import .gbXML. With the plugin, SketchUp is able to both import and export .gbXML files.

\section{Conclusions}

Interoperability through the BIM platform offers one solution to the problem of integration. It reduces the time needed to develop a building and also assures that when the building is put into operation it will meet the design intent. IFCs and gbXMLs seems to be very promising standards that facilitate data interoperability, particularly for building thermal performance tools.

The IFC adopts a standard data model approach to providing interoperability. A different solution to providing integration is that of integrated systems, which can be defined as multipurpose tools that combine many different views (both data and functionality). In addition, gbXML is a schema developed to facilitate a common interoperability model integrating a myriad of design and development tools used in the building industry. GbXML is currently integrated into a range of CAD software and engineering tools.

The gbXML format provides functionality to exchange simplified building geometry and some limited HVAC information, but needs to be extended to allow data exchange of complete HVAC definitions and schedules. The IFC model intentionally contains more thorough definitions across all disciplines and life-cycle phases. However, for a reliable data exchange these definitions need to be implemented in software applications and thoroughly tested. In particular, the HVAC domain in the IFC model still needs such an implemented definition to provide the foundation for exchange related to HVAC data.

Interoperability between BIM-based design and energy simulation tools can improve the workflow between design deliverables and analysis applications. The challenge that is facing the BIM is to assure utmost interoperability by fluidizing model representation, allowing low and high resolution building models that correspond to all design phases and allow a design team based model. Several technical barriers that BIM-based thermal simulation tools continue to face today are: long analytical model preparation times, missing or invalid data in architectural models and inconsistent conversion of architectural models to thermal models.

Automated transactions between the tools, however, require that the information be improved, so as not to be fragmented in the passage between architectural data and thermal engineering data and to guarantee the tool's workflow. These improvements must be evaluated through a series of interoperability test to ensure consistency between all participants using AEC software.

Interoperability between BIM and energy analysis programs is a developing area and the potential of BIM in terms of energy analysis has not been completely optimized as yet. Until now, BIM software has been especially oriented toward architecture, with such developments as Autodesk Revit, Bentley Architecture, Graphisoft/Bentley ArchiCAD, and Vectorworks have focused primarily on modeling and refining building geometry. For example, to perform an energy analysis especially a more 
comprehensive, detailed and specialized thermal analysis, users have sometimes relied on stand-alone thermal software that creates its own geometry.

Although the functionality of the popular building thermal tools has progressed significantly in the past few years, much of the potential of their interoperability through BIM remains largely untapped. Further work is needed to determine if the appropriate design information for use in thermal analyses can be captured within a building information model, in particular their highest priority interoperability enhancements for the purposes of sustainable building design.

\section{Acknowledgments}

This work would not have been possible without the support of many people. The authors wish to express their gratitude to Gunzo Team of ENSAM ParisTech Cluny, for their help, as well as providing the laboratory and necessary information regarding the research.

\section{References}

1. Attia, S. Building Performance Simulation Tools: Selection Criteria and User Survey; Université Catholique de Louvain: Louvain La Neuve, Belgium, 2010.

2. U.S. General Services Administration (US GSA). Statsbygg and Senate, Information Delivery Manual (IDM) for BIM Based Energy Analysis as Part of the Concept Design BIM 2010. Available online: www.blis-project.org/IAI-MVD/IDM/BSA-002/PM_BSA-002.pdf (accessed on 12 January 2013).

3. Energy Efficiency and Renewable Energy (EERE). Building Energy Software Tools Directory, U.S. Department of Energy. Available online: http://apps1.eere.energy.gov/buildings/tools_directory/ (accessed on 18 January 2013).

4. Welle, B.; John, H.; Zack, R. ThermalOpt: A Methodology for automated BIM-based multidisciplinary thermal simulation for use in optimization environments. Build. Simul. 2011, 4, 293-313.

5. Maile, T.; Fischer, M.; Bazjanac, V. Building Energy Performance Simulation Tools-A Life-Cycle and Interoperable Perspective; Stanford University: Stanford, CA, USA, 2007.

6. Fanger, P.O. Thermal Comfort, Analysis and Applications in Environmental Engineering; McGraw-Hill Book Company: New York, USA, 1970.

7. Kumar, S. Interoperability between Building Information Models (BIM) and Energy Analysis Programs. M.S. Thesis, School Of Architecture, University Of Southern California, Los Angeles, CA, USA, 2008.

8. Froese, T. Future directions for IFC-based interoperability. J. ITcon 2003, 8, 231-246.

9. Rossi, R.M.; Brown, D.; Park, B.; Boser, R. The Integrated Design Process on Paper and in Practice: A Case Study. In Proceedings of the 2009 ASC Region III Conference, Downers Grove, IL, USA, 21-24 October 2009.

10. Stamp, B. The Integrated Design Process and Integrated Project Delivery. In Proceedings of the ASHRAE Technical Conference, Lakewood, CO, USA, 20 April 2012. Available online: https://rockymtnashrae.com/downloads/2011_Technical_Conference/ashrae_tc_2011_sustainability_ integrated_design (accessed on 12 January 2013). 
11. BuildingSMART. Available online: http://www.buildingsmart-tech.org (accessed on 12 January 2013).

12. Haymaker, J.; Welle, B. An Integrated Conceptual Design Process for Energy, Thermal Comfort, and Daylighting; Stanford University: Stanford, CA, USA, 2007.

13. Narowski, P.; Stasierski, J.; Wereszczyński, P. Modeling of Conduction Transfer Functions for Typical Thermal Bridges Identified in BIM Data. In Proceedings of the 12th Conference of International Building Performance Simulation Association, Sydney, Australia, 14-16 November 2011.

14. Sullivan, J. Current BIM Interoperability Methods; Autodesk Business Development: McLean, VA, USA, 2011.

15. Dong, B.; Lam, K.P.; Huang, Y.C.; Dobbs, G.M. A Comparative Study of the IFC and gbXML Informational Infrastructures for Data Exchange in Computational Design Support Environments. In Proceedings of Building Simulation, Beijing, China, 3-6 September 2007.

16. Dennis, K.; Roth, S.; Rosen, S.L. Using BIM in HVAC design. ASHRAE J. 2010, 52, $24-32$.

17. gbXML, Open Green Building XML. Available online: http://www.gbxml.org (accessed on 16 January 2013).

18. CAD-magazine and btpinformatic.fr. De la conception numérique au PLM, Architecture: Les Défies des Nouvelles Réglementations Environnementales, Numéro spécial Batimat, France, Novembre 2011 [in French]. Available online: http://www.btpinformatic.fr/architecture (accessed on 18 May 2013).

19. Cormier, A.; Sylvain, R.; Pierrick, R.; Louis, S.; Etienne, W. Towards a BIM-Based Service Oriented Platform: Application to Building Energy Performance Simulation. In Proceedings of the 12th Conference of International Building Performance Simulation Association, Sydney, Australia, 14-16 November 2011.

20. Laine, T.; Hänninen, R.; Karola, A. Benefits of BIM in the Thermal Performance Management. In Proceedings of the Building Simulation 2007, Beijing, China, 3-6 September 2007.

21. Crawley, D.B.; Jon, W.H.; Kummert, M.; Griffith, B.T. Contrasting the capabilities of building energy performance simulation programs. J. Build. Environ. 2008, 43, 661-673.

22. Dubois, M.C.; Horvat, M. State-of-the-Art of Digital Tools Used by Architects for Solar Design; IEA SHC: Paris, France, 2012; pp. 22-115.

23. Design Performance. Available online: http://www.designperformance.net/?page_id=55 (accessed on 10 January 2013).

24. DesignBuilder. Available online: http://www.designbuilder.co.uk (accessed on 10 January 2013).

25. Ecotect Analysis, Sustainable Building Design Software. Available online: http://usa.autodesk.com /ecotect-analysis/ (accessed on 10 January 2013).

26. Thermal: Analysis Methods. Available online: http://wiki.naturalfrequency.com/wiki/Thermal_ Analysis_Methods (accessed on 10 January 2013).

27. EnergyPlus-Energy Simulation Software. Available online: http://www.eere.energy.gov/ buildings/energyplus/ (accessed on 12 January 2013).

28. Hirsch, J.J. Associates in collaboration with Lawrence Berkeley National Laboratory. eQUEST. Available online: http://www.doe2.com/eQuest/ (accessed on 12 January 2013). 
29. Autodesk-Autodesk Green Building Studio. Available online: http://usa.autodesk.com/greenbuilding-studio/ (accessed on 12 January 2013).

30. Korhonen, M.; Laine, T. Energy Analysis Software Evaluation BIM Interface and Interoperability; Granlund: Eskilstuna, Sweden, 2008.

31. EQUA. IDA ICE-Indoor Climate and Energy; EQUA: Stockholm, Sweden, 2013. Available online: http://www.equa.se (accessed on 13 January 2013).

32. Integrated Environmental Solutions (IES). Available online: http://www.iesve.com/ (accessed on 13 January 2013).

33. RIUSKA-Energy Simulation Tool for the Entire Building Life Cycle. Available online: http://www2.granlund.fi/en/services/granlund-software-applications/riuska/ (accessed on 13 January 2013).

(C) 2013 by the authors; licensee MDPI, Basel, Switzerland. This article is an open access article distributed under the terms and conditions of the Creative Commons Attribution license (http://creativecommons.org/licenses/by/3.0/). 